\title{
Dense Deposit Disease Associated With Monoclonal Gammopathy of Undetermined Significance
}

\author{
Sanjeev Sethi, MD, PhD1, William R. Sukov, MD1, Yuzhou Zhang, PhD², Fernando C. \\ Fervenza, MD, PhD ${ }^{4}$, Donna J. Lager, MD ${ }^{1}$, Dylan V. Miller, MD ${ }^{1}$, Lynn D. Cornell, MD¹, \\ Srivilliputtur G. Santhana Krishnan, $\mathbf{M D}^{5}$, and Richard J. H. Smith, MD ${ }^{2,3}$ \\ ${ }^{1}$ Department of Laboratory Medicine and Pathology, Rochester, MN, 55905 \\ ${ }^{2}$ Molecular Otolaryngology and Renal Research Laboratories, Division of Nephrology, Carver \\ College of Medicine, lowa City, IA \\ ${ }^{3}$ Department of Internal Medicine, Division of Nephrology, Carver College of Medicine, lowa City, \\ IA \\ ${ }^{4}$ Department of Internal Medicine, Division of Nephrology and Hypertension, Mayo Clinic, \\ Rochester, MN \\ ${ }^{5}$ Renal Associates of West Michigan, Grand Rapids, Michigan
}

\begin{abstract}
Dense deposit disease (DDD) is a rare glomerular disease that typically affects children and young adults and much less commonly older patients. The pathophysiology underlying DDD is uncontrolled activation of the alternative pathway (AP) of complement cascade most frequently secondary to an autoantibody to $\mathrm{C} 3$ convertase called $\mathrm{C} 3$ nephritic factor, although mutations in factor $\mathrm{H}$ and auto-antibodies to this protein can impair its function and also cause DDD. Since 1995, we have diagnosed DDD in 14 patients 49 years of age or older; ten of these patients $(71.4 \%)$ carry a concomitant diagnosis of monoclonal gammopathy of undetermined significance (MGUS). In one of ten, the index case described herein, we evaluated the AP and demonstrated low serum AP protein levels consistent with complement activity, heterozygosity for the H402 allele of factor $\mathrm{H}$, and low levels of factor $\mathrm{H}$ autoantibodies, which can affect the ability of factor $\mathrm{H}$ to regulate AP activity. In aggregate, these findings suggest in some adults with MGUS, DDD may develop as a result of autoantibodies to factor $\mathrm{H}$ (or other complement proteins) that on a permissive genetic background (the $\mathrm{H} 402$ allele of factor $\mathrm{H}$ ) lead to dysregulation of the AP with subsequent glomerular damage. Thus DDD in some older patients may be a distinct clinicopathologic entity that represents an uncommon complication of MGUS.
\end{abstract}

C) 2010 The National Kidney Foundation, Inc. Published by Elsevier Inc. All rights reserved.

Corresponding author:, Sanjeev Sethi, M.D., Ph.D., Department of Laboratory Medicine and Pathology, 200 First St SW, Rochester, MN, Telephone: (507) 284-1192, Fax: (507), sethi.sanjeev@mayo.edu.

Publisher's Disclaimer: This is a PDF file of an unedited manuscript that has been accepted for publication. As a service to our customers we are providing this early version of the manuscript. The manuscript will undergo copyediting, typesetting, and review of the resulting proof before it is published in its final citable form. Please note that during the production process errors may be discovered which could affect the content, and all legal disclaimers that apply to the journal pertain.

Financial Disclosure: The authors declare that they have no relevant financial interests.

Supplementary Material

Item S1: Detailed Materials and Methods.

Note: The supplementary material accompanying this article (doi:

Descriptive Text for Online Delivery

Hyperlink: Supplementary Item S1 (PDF)

About: Detailed materials and methods. 


\section{INDEX WORDS}

Dense deposit disease; monoclonal gammopathy; MGUS; factor $\mathrm{H}$ antibodies

\section{Background}

Dense deposit disease (DDD), also known as membranoproliferative glomerulonephritis type II, is a rare kidney disease that primarily affects children and young adults, who typically present with acute nephritis, proteinuria or nephrotic syndrome. Their long-term prognosis to retain native kidney function is poor. DDD in adults is less common and the mechanisms of pathogenesis in this age group are less well understood. $(1,2)$

Recent findings have shown that DDD results from a perturbation of the alternative pathway (AP) of complement cascade, resulting in continual fluid-phase complement activation. (1,

2) This pathophysiology is supported by exceedingly low $\mathrm{C} 3$ serum levels and the presence of C3 breakdown products and terminal complement components in DDD glomeruli as resolved by laser capture microscopy followed by liquid chromatography and mass spectrometry. (3) The mechanisms that contribute to complement dysregulation are varied and include the presence of $\mathrm{C} 3$ nephritic factor ( $\mathrm{C} 3 \mathrm{NeF}$; an autoantibody to $\mathrm{C} 3$ convertase), functional deficiency of factor $\mathrm{H}$ protein, and mutations or specific allele variants of a number of different complement genes. $\mathrm{C} 3 \mathrm{NeF}$ stabilizes the typically nascent $\mathrm{C} 3$ convertase complex, while functional deficiency of factor $\mathrm{H}$ protein impairs fluid-phase AP control. The mechanisms by which mutations and allele variants of complement genes lead to DDD are varied and in many cases have not been elucidated. (4-6)

On light microscopy of a kidney biopsy, DDD can exhibit a membranoproliferative pattern, although a variety of other histologies are possible including focal segmental glomerulosclerosis, focal or diffuse proliferative changes, and focal or segmental necrotizing or crescentic glomerular lesions. $(7,8)$ Direct immunofluorescence microscopy must demonstrate intense $\mathrm{C} 3$ staining of the glomerular capillary walls and mesangium in the absence of staining for immunoglobulins and C1q. The definitive diagnosis, however, is based on the identification of characteristic large wavy "sausage-shaped" intramembranous electron dense deposits by electron microscopy. $(1,7)$

In this present study, we show that DDD in older patients is often associated with an underlying monoclonal gammopathy of undetermined significance (MGUS). Furthermore, work up in one patient showed low serum AP proteins, a variant allele at amino acid 402 allele of factor $\mathrm{H}$, and the presence of antibodies to factor $\mathrm{H}$. These findings are consistent with MGUS-related AP dysregulation leading to DDD.

\section{Case Vignette}

A 58-year-old woman presented for follow-up of hypertension and chronic kidney disease. The patient had a past history significant for poorly controlled hypertension and had undergone renal artery stenting 3 years previously. Her blood pressure was reasonably well controlled and her baseline serum creatinine was $3.45 \mathrm{mg} / \mathrm{dL}(304.98 \mu \mathrm{mol} / \mathrm{L})$. There was no history of dysuria, chest pain, shortness of breath, nausea, vomiting, fever, chills or cough. On physical examination, the patient had mild lower extremity edema. Pertinent laboratory findings included a serum creatinine of $7.39 \mathrm{mg} / \mathrm{dL}(653.28 \mu \mathrm{mol} / \mathrm{L})$ and a serum urea nitrogen of $65 \mathrm{mg} / \mathrm{dL}(23.21 \mathrm{mmol} / \mathrm{L})$. C3 levels were low at $0.52 \mathrm{mg} / \mathrm{mL}(0.52 \mathrm{~g} / \mathrm{L}$; reference range $0.8-2 \mathrm{mg} / \mathrm{mL}[0.8-2 \mathrm{~g} / \mathrm{L}])$, while $\mathrm{C} 4$ was normal at $0.26 \mathrm{mg} / \mathrm{mL}(0.26 \mathrm{~g} / \mathrm{L}$; reference range $0.15-0.5 \mathrm{mg} / \mathrm{mL}[0.15-0.5 \mathrm{~g} / \mathrm{L}])$. Urine dipstick showed blood (3+) and protein (3+), and a urinalysis showed 15-25 RBCs/HPF with many dysmorphic RBCs. 
The patient was admitted in the hospital for dialysis. As a part of her routine work up, serum protein electrophoresis was performed, showing a monoclonal gammopathy of $0.4 \mathrm{gm} / \mathrm{dL}$. Urine electrophoresis also showed the monoclonal gammopathy. Serum immunofixation results revealed a monoclonal $\mathrm{IgG} \kappa$. Twenty-four hour urine protein demonstrated 11 grams of protein/day, of which $470 \mathrm{mg}$ or $4.2 \%$ represented her monoclonal gammopathy.

A kidney biopsy done to evaluate the cause of kidney failure consisted of three cores that contained both renal cortex and medulla. Of the 12 glomeruli, four were globally sclerosed and two showed small cellular crescents. All glomeruli had proliferative features with endocapillary proliferation, mesangial expansion with increase in matrix and cellularity, thickening of the glomerular basement membranes, subendothelial expansion with cellular elements, and new basement formation resulting in double contours. There was moderate interstitial inflammation, moderate tubular atrophy and interstitial fibrosis. Arteries and arterioles showed mild sclerosis of the intima.

Direct immunofluorescence microscopy showed intense staining for C3 (3+) in the mesangium and along the capillary walls. Staining for immunoglobulins (including $\kappa$ and $\lambda$ light chains) and C1q was negative. Electron microscopy showed thickening of the glomerular basement membranes by intramembranous and subendothelial accumulation of dense osmiophilic material. In a few loops, the material completely lined the capillary loops, while in others it showed a patchy segmental distribution. The mesangium showed accumulation of similar dense osmiophilic material. Deposits were not present along the tubular basement membranes. Representative light, immunofluorescence, and electron microscopy findings are shown in figure 1.

On the basis of the kidney biopsy, a diagnosis of DDD was made. To try and identify the AP perturbation underlying the DDD, evaluation of factors involved in this pathway was performed; detailed information on the methodology used is described in Item S1 (provided as online supplementary material available with this article at www.ajkd.org). C3NeF, the autoantibody typically found in cases of DDD, was undetectable by enzyme-linked immunosorbent assay (ELISA). AP complement activity was low at $25.8 \%$ (reference range, 65-130\%), indicating consumption of AP proteins in the serum secondary to complement activation. The hemolytic assay, which measures complement-mediated lysis of sheep erythrocytes secondary to cell surface activation of AP, was normal ( $<3 \%$ hemolysis). As determined by ELISA, factor $\mathrm{H}$ autoantibodies were positive at a titer of 1:100 $(<1: 50$ is considered a normal reading). Genetic testing established that the patient was heterozygous at the position in the $C F H$ gene coding for amino acid 402, with one copy of the gene encoding a histidine at this position, and the other copy encoding the ancestral tyrosine allele; no variants in the $C F I$ and $C D 46$ genes were detected. These findings are summarized in Table 1.

\section{Pathogenesis}

DDD is a rare condition that classically afflicts children or young adults. It progresses to end-stage renal disease in $50 \%$ of patients within 10 years of diagnosis and usually recurs following kidney transplant, often leading to graft failure. While cases of DDD affecting older patients are reported, it is less common in this patient population. MGUS, in contrast, is a common disease of older patients with a prevalence ranging from $3.7 \%$ in those 50 years of age to $7.5 \%$ in those older than 80 years.

Given the rarity of DDD in older adults, and to investigate the possible association of DDD with MGUS in this population, we reviewed cases of patients aged 49 years or older who had been given a diagnosis of DDD at our institution. We identified 14 patients, of whom 10 
(71.4\%; 8 women, 2 men) also carried a diagnosis of MGUS. Age in this group ranged from 49 to 77 years, with a median of 60 years and mean of 61.1 years. In all patients, a monoclonal IgG protein was identified by serum protein electrophoresis although one patient also had a monoclonal IgA (biclonal). Six patients had associated monoclonal $\kappa$ light chains and four had monoclonal $\lambda$ light chains.

The clinical features and the associated light microscopy, direct immunofluorescence and electron microscopy findings on kidney biopsy for each patient are presented in Table 2 . Four patients were recently diagnosed (cases 7, 8, 9 [index case], and 10) and thus long-term follow-up is not available. None of the patients had progressed beyond MGUS at the time of kidney biopsy and therefore none of the patients was receiving chemotherapy or other treatment for plasma cell dyscrasia or associated disease. Six patients had progressed to endstage renal disease; one patient received an transplant but developed recurrent disease within one month, leading to graft failure.

Histologically, a well-defined membranoproliferative pattern was seen in the biopsies from six patients. The glomeruli in these six biopsies showed a mild-to-moderate degree of mesangial hypercellularity and sclerosis, thickening of the glomerular basement membranes, double contour formation and lobular accentuation of glomerular tufts. As described in the Case Vignette, the biopsy from the index case showed MPGN and small cellular crescents. One case showed nodular mesangial sclerosis, two cases showed a predominantly mesangial proliferative pattern (one of which was nodular appearing), and one case showed focal segmental glomerulosclerosis with fibrocellular crescents. All biopsies showed capillary loop and mesangial staining for $\mathrm{C} 3$ on direct immunofluorescence, while staining for immunoglobulins, $\kappa$ or $\lambda$ light chains were negative. Electron microscopy showed the diagnostic intramembranous deposits of DDD. The intramembranous electron dense deposits did not show discernable substructure on high magnification and did not appear granular. No granular tubular basement membrane deposits reminiscent of light chain deposition disease were present.

The observation that $71.4 \%$ of patients 49 years of age and older who were diagnosed with DDD on kidney biopsy also carried an established diagnosis of MGUS is much higher than expected and raises the possibility of a cause-and effect relationship between the two conditions. Since all patients identified in the present study carried the diagnosis of MGUS prior to the development of kidney disease, we considered the possibility that DDD may be a consequence of the existing MGUS. A search of the literature also revealed one case report of DDD associated with MGUS. (9)

\section{Recent Advances}

Several studies have established a link between DDD and dysregulation of the AP of complement. $(1,2,4-6,10)$ Under normal conditions, the AP is in a state of equilibrium with spontaneous baseline low-level C3 activation due to a process known as "tick-over". Tickover leads to formation of $\mathrm{C} 3$ convertase, with subsequent cleavage of additional $\mathrm{C} 3$ and formation of more $\mathrm{C} 3$ convertase, a process enhanced by positive feedback and referred to as the $\mathrm{C} 3$ amplification loop. To prevent untoward damage, the activity of this system is under tight control by a number of fluid-phase and surface-bound proteins known as regulators of complement activation (RCAs). The most important fluid-phase RCA is factor H. (5)

Dysregulation of fluid-phase AP control can occur as a result of uninhibited or poorly inhibited $\mathrm{C} 3$ convertase activity caused by $\mathrm{C} 3 \mathrm{NeF}$, which binds to and stabilizes the $\mathrm{C} 3$ convertase complex. This interaction increases the half life of $\mathrm{C} 3$ convertase leading to $\mathrm{C} 3$ consumption, which drives down serum $\mathrm{C} 3$ and increases serum $\mathrm{C} 3$ breakdown products. 
Concentrations of $\mathrm{C} 3 \mathrm{NeF}$ can vary over time in patients with DDD. (1) Interestingly, in the most recent case of DDD with MGUS, preliminary studies suggest positive titers of $\mathrm{C} 3 \mathrm{NeF}$ (case 10; data not shown, remaining studies are pending).

Factor $\mathrm{H}$ abnormalities have also been linked to DDD. For example, if factor $\mathrm{H}$ is either absent or non-functional, $\mathrm{C} 3$ convertase activity increases. (5) Absence of factor $\mathrm{H}$ can be due to mutations that preclude its cellular secretion, as has been shown in the first animal model of DDD, the Norwegian Yorkshire pig, which carries a pathological isoleucine to arginine mutation at amino acid 1166 (located in short consensus repeat [SCR] 20) that blocks protein secretion. (11) Non-functional factor $\mathrm{H}$, in contrast, can be due to either mutations or autoantibodies to specific domains that impair normal function. $(6,12-16)$ Thus DDD can arise secondary to either inherited or acquired factors. (14)

We propose that older patients with MGUS may develop DDD if monoclonal immunoglobulins alter RCA protein function. Although autoantibodies to factor $\mathrm{H}$ are best studied and characterized, it is not unreasonable to hypothesize that autoantibodies to other complement proteins could have similar effects. In the case we present (case 9), serum levels of AP proteins were low consistent with AP consumption and decreased regulatory activity of factor $\mathrm{H}$ secondary to autoantibodies to this protein. However, it should be pointed out that while we have demonstrated autoantibodies to factor $\mathrm{H}$, we have not determined whether the factor $\mathrm{H}$ autoantibody is the same as the monoclonal immunoglobulin produced as a result of the MGUS. Nearly 20 years ago, Meri and colleagues described a similar case in which purified monoclonal light chains activated the AP by directly interacting with factor H. (17) More recently, Jokiranta et al isolated monoclonal immunoglobulin light chains from a patient with DDD and demonstrated the ability of these autoantibodies to activate the AP by blocking the third short consensus repeat (SCR3) of factor $\mathrm{H}$, an important site for fluid-phase control of the $\mathrm{C} 3$ convertase. (18)

Our hypothesis that monoclonal immunoglobulins can act in the fluid phase to impair AP regulation is supported by laser capture and mass spectrometry studies that fail to detect monoclonal light chains in glomeruli in DDD patients (data not shown). These studies also confirmed our previously reported findings that DDD glomeruli contain complement factors of both the alternative and terminal complement components. (3)

A permissive genetic background, as found in our patient, is probably also important. An association study has shown that the $\mathrm{H} 402$ allele (ie, a histidine instead of tyrosine [Y] residue at amino acid 402) of factor $\mathrm{H}$ is found in $85 \%$ of persons with DDD.(13) Comparative studies of the $\mathrm{H} 402$ and Y402 alleles of factor $\mathrm{H}$ show that the former has reduced heparin and endothelial cell binding properties, which may make the glomerular basement membrane more susceptible to complement-mediated injury. Figure 2 shows the proposed mechanism of development of DDD in MGUS patients.

\section{Summary}

We present a series of ten patients with an established diagnosis of MGUS who subsequently developed DDD as confirmed by kidney biopsy. Work up of the index case of MGUS and DDD showed low AP proteins, autoantibodies to factor $\mathrm{H}$ and heterozygosity for the $\mathrm{H} 402$ allele of factor $\mathrm{H}$. We suggest that DDD associated with MGUS is a distinct clinicopathologic entity associated with a poor clinical outcome caused by monoclonal immunoglobulins binding to and inactivating factor $\mathrm{H}$ (or other complement proteins, including development of $\mathrm{C} 3 \mathrm{NeF}$ ). Many cases of MGUS are followed by monitoring monoclonal immunoglobulins, and although no specific therapy is offered, we propose that if DDD has developed, treating MGUS with chemotherapy should be considered. 


\section{Supplementary Material}

Refer to Web version on PubMed Central for supplementary material.

\section{Acknowledgments}

Support: This research was supported in part by National Institute of Diabetes and Digestive and Kidney Diseases grant DK074409 to Drs Sethi and Smith.

\section{References}

1. Appel GB, Cook HT, Hageman G, et al. Membranoproliferative Glomerulonephritis Type II (Dense Deposit Disease): An Update. J Am Soc Nephrol. 2005; 16(5):1392-1403. [PubMed: 15800116]

2. Smith RJH, Alexander J, Barlow PN, et al. New Approaches to the Treatment of Dense Deposit Disease. J Am Soc Nephrol. 2007; 18(9):2447-2456. [PubMed: 17675665]

3. Sethi S, Gamez JD, Vrana JA, et al. Glomeruli of Dense Deposit Disease contain components of the alternative and terminal complement pathway. Kidney Int. 2009; 75(9):952-960. [PubMed: 19177158]

4. Pickering MC, Cook HT, Warren J, et al. Uncontrolled C3 activation causes membranoproliferative glomerulonephritis in mice deficient in complement factor H. Nat Genet. 2002; 31(4):424-428. [PubMed: 12091909]

5. Zipfel PF. Complement factor H: physiology and pathophysiology. Semin Thromb Hemost. 2001; 27(3):191-199. [PubMed: 11446652]

6. Licht C, Schlötzer-Schrehardt U, Kirschfink M, Zipfel PF, Hoppe B. MPGN II - genetically determined by defective complement regulation? Pediatric Nephrology. 2007; 22(1):2-9. [PubMed: 17024390]

7. Nasr SH, Valeri AM, Appel GB, et al. Dense Deposit Disease: Clinicopathologic Study of 32 Pediatric and Adult Patients. Clin J Am Soc Nephrol. 2009; 4(1):22-32. [PubMed: 18971369]

8. Sethi S, Sahani M, Oei LS, Rao R. Crescentic glomerulonephritis and dense deposit disease in a woman with breast carcinoma on immunosuppressive chemotherapy. American journal of kidney diseases. 2004; 44(3):e33-e37. [PubMed: 15332237]

9. Sepandj F, Trillo A. Dense deposit disease in association with monoclonal gammopathy of unknown significance. Nephrol Dial Transplant. 1996; 11(11):2309-2312. [PubMed: 8941598]

10. Pickering MC, Warren J, Rose KL, et al. Prevention of C5 activation ameliorates spontaneous and experimental glomerulonephritis in factor H-deficient mice. Proceedings of the National Academy of Sciences USA. 2006; 103(25):9649-9654.

11. Høgåsen K, Jansen JH, Mollnes TE, Hovdenes J, Harboe M. Hereditary porcine membranoproliferative glomerulonephritis type II is caused by factor $\mathrm{H}$ deficiency. The Journal of Clinical Investigation. 1995; 95(3):1054-1061. [PubMed: 7883953]

12. Lau KK, Smith RJ, Kolbeck PC, Butani L. Dense deposit disease and the factor H H402 allele. Clinical and Experimental Nephrology. 2008; 12(3):228-232. [PubMed: 18224273]

13. Abrera-Abeleda MA, Nishimura C, Smith JLH, et al. Variations in the complement regulatory genes factor $\mathrm{H}(\mathrm{CFH})$ and factor $\mathrm{H}$ related 5 (CFHR5) are associated with membranoproliferative glomerulonephritis type II (dense deposit disease). J Med Genet. 2006; 43(7):582-589. [PubMed: 16299065]

14. Licht C, Fremeaux-Bacchi V. Hereditary and acquired complement dysregulation in membranoproliferative glomerulonephritis. Thromb Haemost. 2009; 101(2):271-278. [PubMed: 19190809]

15. Montes T, Goicoechea de Jorge E, Ramos R, et al. Genetic deficiency of complement factor H in a patient with age-related macular degeneration and membranoproliferative glomerulonephritis. Mol Immunol. 2008; 45(10):2897-2904. [PubMed: 18336910]

16. Rose KL, Paixao-Cavalcante D, Fish J, et al. Factor I is required for the development of membranoproliferative glomerulonephritis in factor H-deficient mice. The Journal of Clinical Investigation. 2008; 118(2):608-618. [PubMed: 18202746] 
17. Meri S, Koistinen V, Miettinen A, Törnroth T, Seppälä IJ. Activation of the alternative pathway of complement by monoclonal lambda light chains in membranoproliferative glomerulonephritis. $\mathbf{J}$ Exp Med. 1992; 175(4):939-950. [PubMed: 1532415]

18. Jokiranta TS, Solomon A, Pangburn MK, Zipfel PF, Meri S. Nephritogenic \{lambda\} Light Chain Dimer: A Unique Human Miniautoantibody Against Complement Factor H. J Immunol. 1999; 163(8):4590-4596. [PubMed: 10510403] 


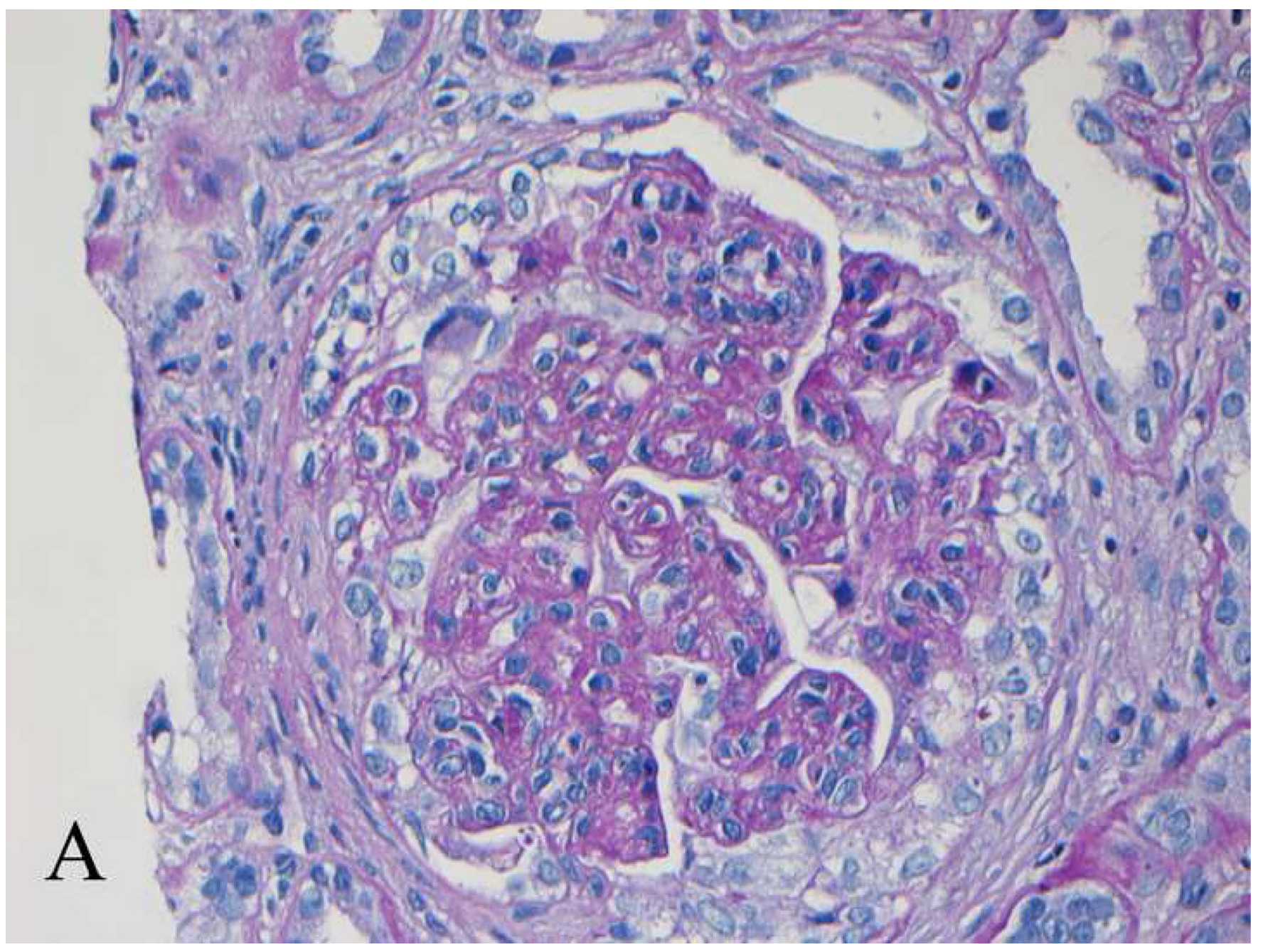

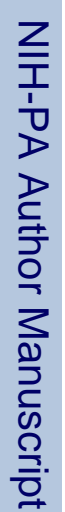




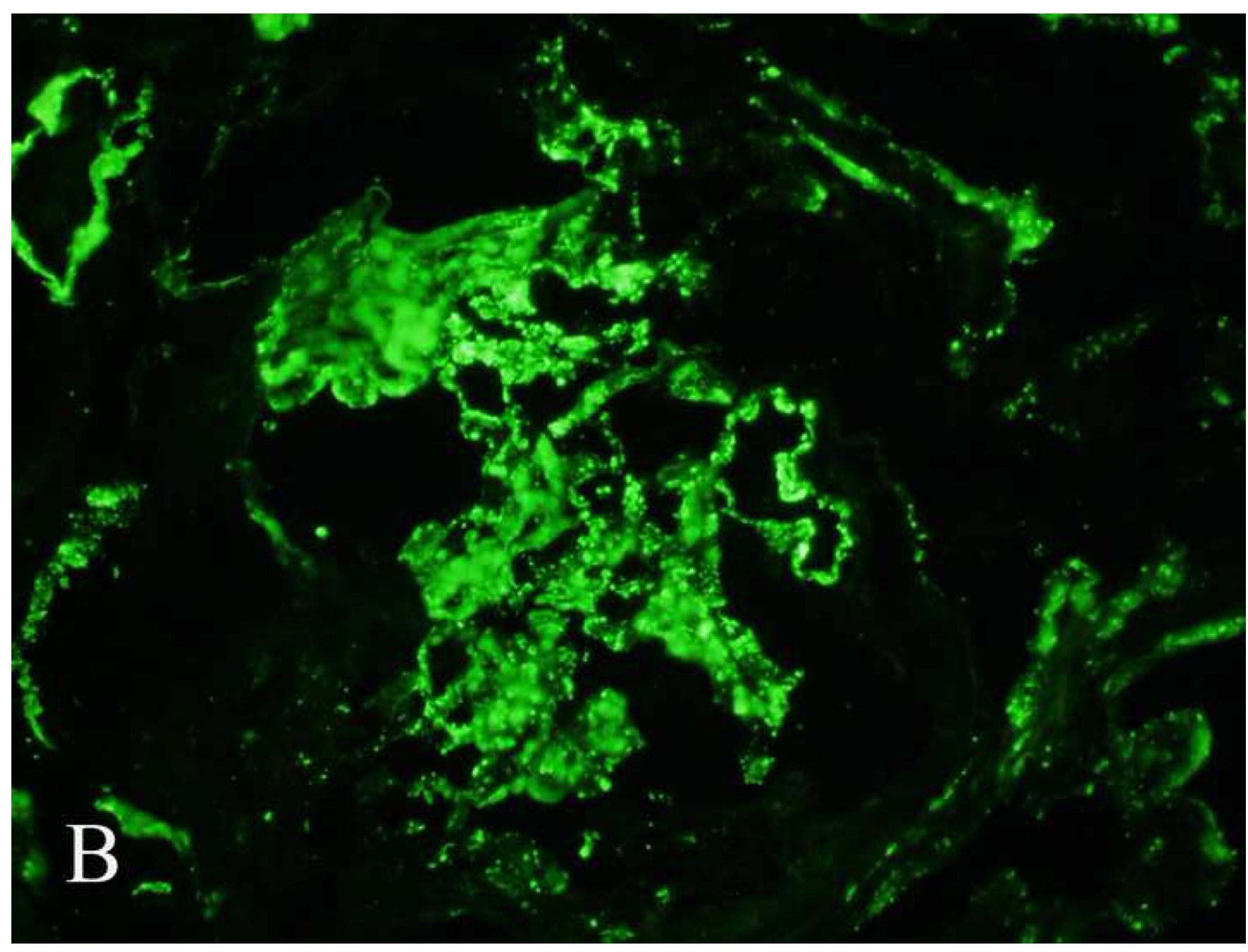

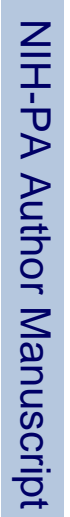




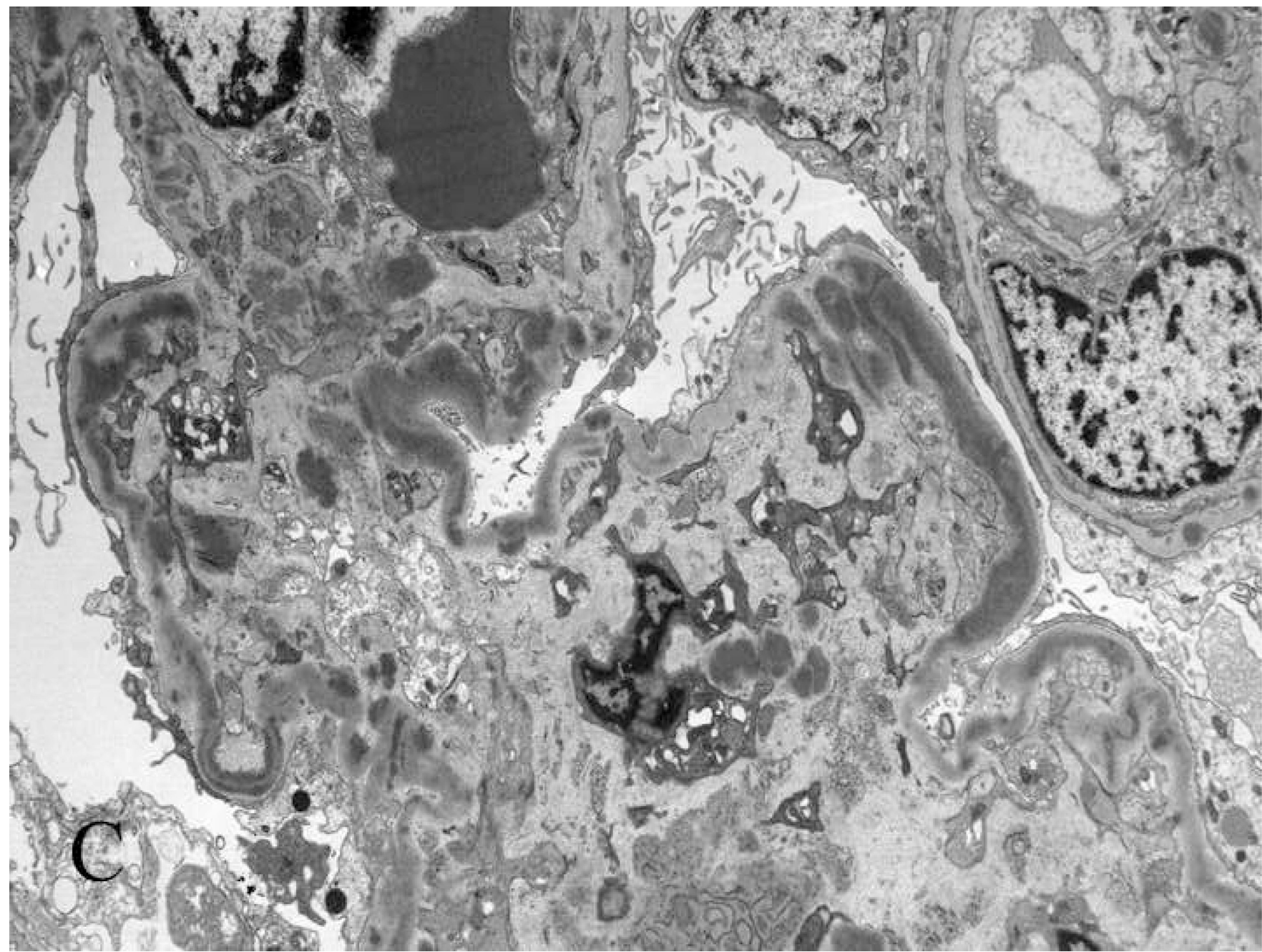

Figure 1.

Light, immunofluorescence and electron microscopy findings in a case of dense deposit disease associated with monoclonal gammopathy of undetermined significance (case 9, Table 1). (A) Light microscopy: periodic acid-Schiff stained section showing a membranoproliferative pattern of injury with thickened glomerular basement membranes. (B) Immunofluorescence microscopy showing intense C3 staining along the glomerular basement membranes and mesangium. (C) Electron microscopy showing dense intramembranous and mesangial deposits. 


\section{MGUS}

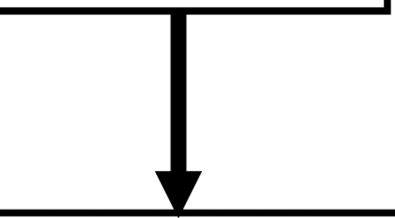

\section{Antibodies to factor $\mathrm{H}$ or RCAs}

\section{H402 allele of factor $\mathrm{H}$}

\section{Dysregulation of the AP of complement}

\section{Dense deposit disease}

Figure 2.

Summary of proposed pathway of dense deposit disease in patients with monoclonal gammopathy of undetermined significance (MGUS).

Abbreviations and definitions: AP, alternative pathway; H402, histidine allele at amino acid 402 of $\mathrm{CFH}$; RCAs, regulators of complement activation. 
Table 1

Work up of alternative pathway of complement in a case of DDD

\begin{tabular}{|l|l|}
\hline Assay & Result \\
\hline C3 nephritic factor (C3NeF) & Negative \\
\hline Alternative pathway functional assay & Low at 25.8\% \\
\hline Hemolytic assay & Negative \\
\hline Factor H autoantibody & Low positive \\
\hline Genetic analysis of factor H & One copy of H402 allele and Y402 allele \\
\hline Genetic analysis of factor I & no variants detected \\
\hline Genetic analysis of $C D 46$ gene & no variants detected \\
\hline
\end{tabular}

DDD, dense deposit disease; $\mathrm{H}$, histidine; $\mathrm{Y}$, tyrosine 


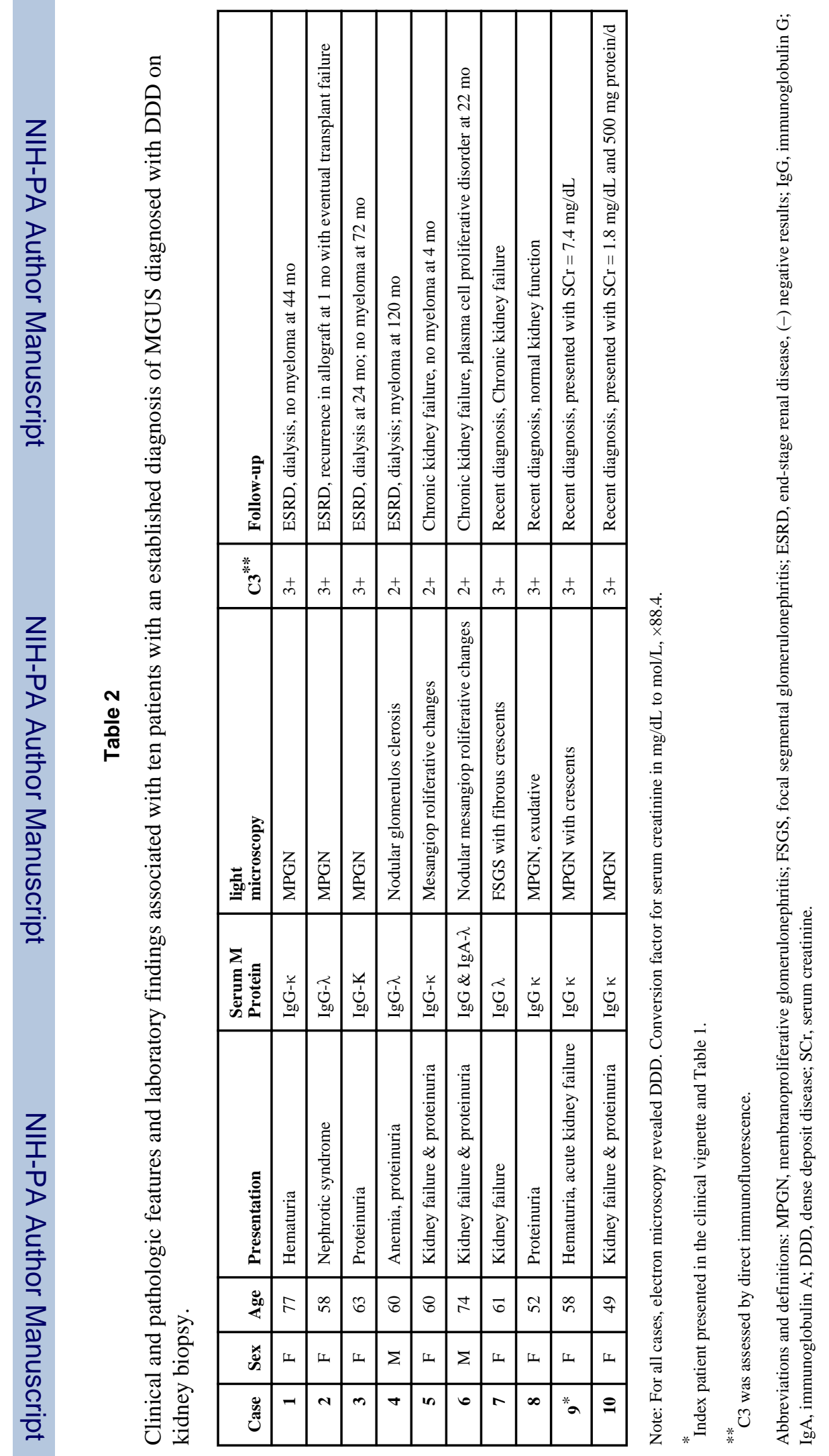

